Katarzyna TWOREK ${ }^{1}$

Katarzyna WALECKA-JANKOWSKA ${ }^{1}$

Anna ZGRZYWA-ZIEMAK ${ }^{1}$

\title{
THE ROLE OF INFORMATION SYSTEMS IN SHAPING INTEGRATIVE LOGIC FOR BUSINESS SUSTAINABILITY
}

\begin{abstract}
The article refers to a valid and current research area, which is the role of information technology (IT) in the formation of business sustainability (BS). The main objective of this article is to identify the role of IT in shaping sustainable organization in the context of different, partly conflicting, approaches to BS and empirical verification of the proposed theoretical framework. The article describes key differences between BS approaches in case cognitive logic (reductionist versus integrative logic) and axiological (individualistic-egoistic versus holistic-altruistic axiology) distinction. Theoretical role of IT in shaping integrative logic for BS is identified and presented. The proposed theoretical concept is empirically verified. The verification is based on empirical studies conducted in 400 SMEs operating in Poland in 2017.
\end{abstract}

Keywords: business sustainability, information technology, IT reliability, organizational performance, system approach

\section{Introduction}

The article refers to the importance of information technology (IT) for transforming the organisation into a more sustainable one. IT reliability is an important concept for every modern organisation. In today's world, the increasing importance of IT can be seen in all kinds of organisations. It becomes a ubiquitous and increasingly significant part of the fabric of most organizations [14] and it is recognised as an important factor influencing the organisation's ability to create competitive advantage [12, 36, 60].

${ }^{1}$ Faculty of Computer Science and Management, Wrocław University of Science and Technology, ul. Łukasiewicza 5, 50-371 Wrocław, Poland, e-mail addresses: anna.zgrzywa-ziemak@pwr.edu.pl, katarzyna.tworek@pwr.edu.pl,katarzyna.walecka-jankowska@pwr.edu.pl 
Hence, it can be stated that one of the most important influences of IT from the perspective of the recent economic changes is its ability to support the systemic approach to organisation management. The systemic approach has gained interest in recent years, mainly because of IT use itself. Organisations are able to use IT more and more efficiently and therefore they are looking for ways which allow them to gain the most benefits from it. A systemic approach is important because of its one more specific role, namely, it is one of two pillars of business sustainability. The concept of business sustainability (BS) is rooted in a broader concept of sustainable development of the world, which is considered as one of the greatest and most urgent challenges that humanity is facing today $[16,65]$. Hence, solutions to promoting BS are becoming particularly important. The main objective of this article is to develop a theoretical framework of IT role in shaping BS taking into consideration the role of the systemic approach in this relation. Moreover, the empirical verification of the proposed theoretical framework is also suggested as a first step to validate the proposed theory.

Since the importance of IT for transforming the organisation into more sustainable one is not studied in a systematic way yet, proposing a theoretical framework concerning this notion is a significant input in the current state of knowledge in this field of study and pertains to the existing research gap in it. The role of IT in building BS has been underlined from the moment this concept arose in the literature. According to Fenny and Ives [19], strategic elements of IT are crucial for sustaining the organisation and make it thrive. Later et al. [34] show that IT can be considered as a unique organisation attribute, which is necessary for the sustainability of the organisation's competitive advantage. Over a decade later, Jeffers [32] states that rare IT resources, which cannot be easily reproduced by the competitors, provide a competitive advantage and underlines that in the 21 st century the properly working, innovative and strategically chosen IT is a necessity for BS. Some of the available research is concentrated on IT value for organisation performance in the context of sustainability (e.g., $[41,49])$.

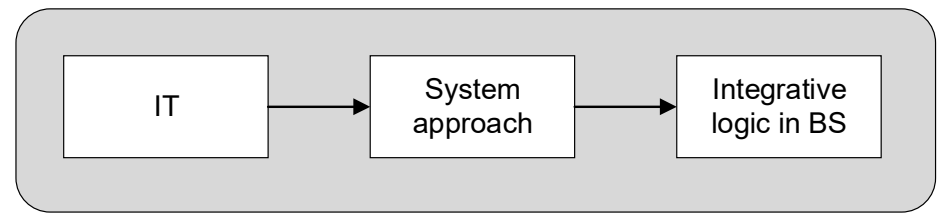

Fig. 1. The relation between IT and BS

However, there is still a lack of understanding of the theoretical foundations of IT role in shaping BS. In this paper, the role of IT in forming integrative logic of BS is discussed and verified as a potential way in which IT influences the BS. IT is recognised as important for system approach in the organisation, and a system approach is an essence of an integrative logic of BS approaches (Fig. 1). 
In this paper, different, mutually exclusive BS approaches are presented. For a full understanding the differences between the multiple approaches BS, two aspects are considered crucial: the dominant cognitive logic (reductionist versus integrative logic), and axiological foundation (individualistic-egoistic versus holistic-altruistic axiology) [22, $45,67]$. The development of a holistic approach to BS, which gives a chance to a significantly positive, critical and relevant impact on society since the planet requires both integrative cognitive logic and holistic-altruistic axiology. The significance of IT in forming the BS integrative logic is identified. IT as a factor supporting a systemic way of organisation operations is discussed. As based on the theoretical analysis of the relation between IT and BS, the hypothesis is formulated that states the more reliable IT is, the more integrated the cognitive logic of BS is. The proposed theoretical concept is empirically verified. This study adopts the model of IT reliability in organisation developed and tested by Tworek [61] and BS measurement approach based on the company's performance, which is the manifestation of how an organisation contributes to sustainable development. The verification is based on empirical studies conducted in 400 SMEs operating in Poland in 2017 (multidimensional correspondence analysis (MCA) was used).

\section{Business sustainability approaches}

BS is a complex, multi-faceted phenomenon, integrating some, often contradictory, conflicting aspects [24]. There are attempts to identify the BS levels, to formulate sustainable business models, to determine the concept of increasing the advancement in the BS, and to build theories of sustainability management [1, 16, 59, 64]. However, approaches to BS presented in the literature and management practice do not allow for the formulation of a single, unambiguous concept of BS [68].

Some researchers recognise the creation of the long-term shareholder value as the essence of BS, where social and environmental concerns are important in the context of opportunities and risks, benefits, and costs, all being crucial for building this value [52]. BS refers here to the survival and development of the organisation as a system $[9,30]$. This approach is appropriate for a reductionist way of perceiving reality, dominated by the logic of parts, which is narrow, short-term and static. Social and environmental issues are seen as separate from the business core. The main assumption concerns the causal relation between social and environmental engagement and economic results [22]. The other assumption refers to the desire to avoid any tensions between the dimensions of the BS, the needs of different stakeholders, and temporal and spatial perspectives.

A radically different perspective is presented by those who see the organisation as a mesoscale social artefact in need of consideration as a possibly potent means of approaching sustainable development' [47]. According to Dyllick and Muff [16], the truly sustainable organisation creates a significantly positive impact in those areas which are 
critical and relevant for the society and the planet. In this context, although the organisation has to generate a profit that allows reconstruction of its potential and its further development, the overriding objective of the organisation is a commitment to the development of the wider socio-ecological system [55]. This approach can be described as an integrative approach [22]. It is characterised by the logic of the whole, which is wide, long-term, dynamic. Social and environmental issues are integral parts of business activity, dominated by the prospect of dynamic interdependence of all dimensions of the BS (economic, social, and environmental). There is also a parallel consideration of the needs of different stakeholders (current and future), different perspectives of time and space (specific to all BS dimensions). Moreover, tensions (between stakeholders, BS dimensions, or temporal perspectives) are treated as normal and potentially beneficial.

Both approaches to the understanding of BS differ not only in the accepted cognitive logic (reductionist versus integrative) but also in an extremely different axiological position $[67,68]$. According to the typology proposed by Papuziński [45], there are two sustainable development axiologies: individualistic-egoistic, and holistic-altruistic. The first, individualistic-egoistic, is characterized by individualism, egoism, acknowledgement of the primacy of rights over good, and the vision of the human being seen as an individual. The second, holistic-altruistic, is marked by altruism, acknowledgement of the primacy of good over right, and the vision of the human being seen as a person. Papuziński [45] clearly points out that the individualistic-egoistic axiology does not allow for the implementation of the principles of generational and intergenerational justice, and rather carries the risk of achieving short-term benefits at the expense of the community. As a result, Zgrzywa-Ziemak [67, 68] proposes two extreme approaches to $\mathrm{BS}$, instrumental and holistic which should be regarded as clearly contradictory to the previous ones in the axiological dimension.

However, as presented in Fig. 2, BS concepts represent also intermediate approaches. The prevailing is the win-win approach, the essence of which is a simultaneous, synergistic, systematic provision of economic, social and environmental benefits [21]. The win-win approach focuses on finding cost-effective areas for the organisation that are at the same time socially and/or environmentally beneficial. This trend is fitted by, for example, the concept of shared value by Porter and Kramer [50] and by the concept of sweet spots by Savitz and Weber [54]. It is the approach that largely adopts an integrative logic. For example, there is a domination of emphasis on integrating social and environmental issues with the basic activities of the organisation (strategic and operational), on the interdependence of all dimensions of BS, on cooperation within and between the organisations. However, proponents of this approach do not seem to recognise that conflicts between aspects of economic, environmental and social management of the organisation are the rule rather than the exception. According to Crane et al. [10], this approach avoids a deeper reflection on the systematic responsibility of the organisation, it does not require a change of moral attitude and it is based on the current assumption of proceeding by one's own interest (the authors discuss the concept of Porter 
and Kramer). Although this idea takes (to some extent) an integrated perception of reality, it remains individualistic-egoistic sustainable development axiology [67].

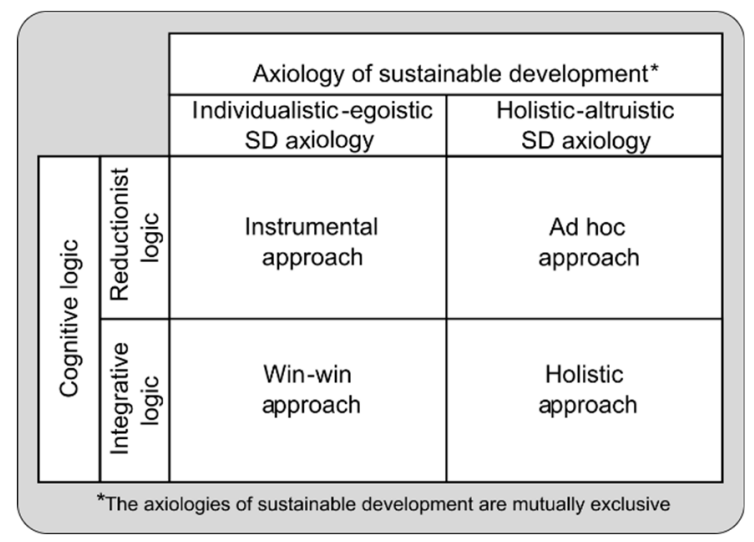

Fig. 2. Business sustainability approaches. Source: [68]

Although ad hoc BS approach is regarded as a manifestation of holistic-altruistic sustainable development axiology, the reductionist cognitive logic dominates. Ad hoc BS approach is manifested by the organisation's involvement in various separate social and environmental initiatives with the lack of integration between them. The short- and long-term perspectives and different needs of stakeholders are perceived as competitive, and not taken into parallel consideration. On the one hand, there is a risk of unintended consequences for the organisation, local community and natural environment, all different in short- and long-term. On the other hand, as Senge et al. [55] indicate, it can also build frustration due to lack of expected results and due to conflicts between different initiatives and efforts.

The approaches to the concept of BS, which are distinguished in theory and in practice, were outlined. There is no reference to all significant differences between them and all tradeoffs characterising each of them. Still, as based on the discussion above, the development of BS in the context of sustainable development challenges requires the development of holistic-altruistic values in the organisation, as only holistic-altruistic axiology gives a chance to resolve the issue of the modern existential world and integrative logic.

This brief analysis helps to emphasise that all the methods, techniques, and tools developed for the formation of the BS contextually result from the approach to BS related to $[22,45,67]^{2}$, namely to holistic-altruistic axiology (the approaches to BS are mutually exclusive in the axiological dimension) and reductionist-integrative logic.

${ }^{2}$ Dimensions, which are the basis for specifying BS approaches, are essentially based on the concept of Gao and Bansal [22]. The authors use concepts of instrumental and integrative approach. In a part of 


\section{Business sustainability and system approach}

Sustainable development challenges are complex, broadly interconnected and dynamic well beyond the reach of any organisation or even country [25]. It is mainly due to the interdisciplinary character of the body of knowledge that pertains to it (natural sciences, regional, societal, economic and technical/engineering ones), the multiplicity, diversity and changeability of interests of different stakeholders affected by it, and tensions between short-term and long-term aspects of it. Senge et al. [55] argue that seeing sustainable development issues as separate and approaching them separately (e.g., water shortages, climate change, poverty) support short-term and opportunistic solutions that do not address deeper imbalances. Coping with SD challenges requires system thinking [55]. This allows one to discover the points of the most effective impact on the system and limits the risk of unintended consequences [18, 55]. Dragomirescu and Bianco [15] indicate that a systems approach has a twofold bearing, namely onto thinking and onto acting. It is useful for conceptualisation and foresight purposes and steering on-theground, actions aimed at achieving sustainable development within specific frameworks of space, time and agency [15]. In his paper, Fiksel [18] discusses crucial requirements for broad adoption of a systems approach to cope with global sustainability.

The systems approach is also viewed as especially valuable for BS [31, 59, 17, 22, 3 , 24]. With reference to the concept of Fath $[18]^{3}$, organisation (as a system) is part of a wider natural and social system. When an organisation is dependent on inflows that cannot be maintained (such as non-renewable energy sources or depleting regenerative capacities), it cannot be considered sustainable. Similarly, the organisation whose outflows cannot be absorbed by the environment or limit the ability of this environment to absorb them in the future also cannot be considered as sustainable $[35,18]$. The organisation is part of a wider social system - the local community, families, culture, and collaborates with different stakeholders to achieve sustainability for the system that the organisation is part of [59]. Organisations provide products and services to societies, contributing to the satisfaction of a number of individual and social needs, but organisations can also have a negative impact on the social system, for example, by generating

\footnotetext{
their work, they apply the concept of instrumental approach to the instrumental motives of social and ecological investments for the financial result. However, in the dominant part of the work, the essence of the analysed approach is the way of understanding and analysing reality which, as indicated by Zgrzywa-Ziemak [67], should be described as consistent with the reductionist approach. Then, it is understandable and justified to oppose it to the "integrated approach". The integrated approach relating to the involvement in social and environmental issues may be caused by instrumental motives (which the authors identify with the orientation on the financial result), and the use of the 'reductionist approach' may be guided by the pursuit of solving key problems in the area of BS (as final/autotelic value and not instrumental).

${ }^{3}$ Fath understands "sustainability" as a holistic property of the system and defines it as "a system's capacity to endure and maintain vital functions" [18].
} 
anxieties, injustices and social tensions [55]. According to Fath [18], what is very important here is what is happening in the system itself - the organisation of the system itself is a necessary property of its durability (what happens to inflows, how they are managed and used). The adaptation of system approach contributes significantly to BS because it emphasises the need to pursue different sustainability aspects simultaneously; what is more, the need to embrace the tensions between different conflicting sustainability aspects rather than dismissing them [37,24]. Tensions and conflicts are inherited in BS concept, for example, in the multidimensional nature of BS $[22,24,30]$, the need to satisfy the needs of different stakeholders - actual and future ones [67] - or the different perspectives of time [2, 22].

However, it should be emphasised that organisations face significant barriers in dealing with the environment, which are characterized by a high degree of volatility, uncertainty, complexity and ambiguity [55]. That is because the human mind is slightly equipped with the ability to analyse complex and dynamic situations [58, 33]. Hence, there is a great need to develop tools and skills for problem analysis and model building, both of which are essential for implementing a system approach in the organisation. However, the crucial step in obtaining those skills is the ability to properly implement all technical aspects of system approach (knowledge of basic blocks building system dynamics - feedbacks, the role of time, basic coupling systems existing in practice), and development of methodologies and tools for dealing with missing and uncertain information; methods for interpretation of multivariate data sets and for multi-objective decision making involving trade-offs among conflicting goals [18]. Nowadays, it seems almost impossible to generate the value for an organisation from system approach (and those skills) without the use of IT, which enables the possibility to implement system approach in a more fluent, organised and transparent way $[12,36]$.

\section{IT as a factor supporting a systemic way of organisation operations}

IT influence on organisation seems to be especially important due to its ability to support integration within the organisation and systemic way of operating. The field of science concerning IT role in the organisation is quite chaotic. Hence, the analysis of literature should always start with some kind of organisation of all available knowledge. In order to fully analyse the potential influence of IT on organisational integration and systemic operations, an in-depth literature analysis was done. It was based on 4 basic IT capabilities, underlining the issue of IT reliability. Among the 4 basic IT capabilities, authors usually name: 
Table 1. IT value models and the dependent variables connected to the system approach

\begin{tabular}{|c|c|c|}
\hline $\begin{array}{l}\text { Independent } \\
\text { variable }\end{array}$ & Dependent factors building IT value & $\begin{array}{l}\text { Created IT value which concerns system } \\
\text { approach to organisational management }\end{array}$ \\
\hline \multirow{2}{*}{ 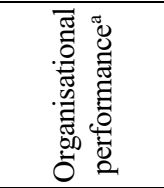 } & IT resources (3R) & $\begin{array}{l}\text { communication and information } \\
\text { flows reorganisation }\end{array}$ \\
\hline & $\begin{array}{l}\text { complementary business resources } \\
\text { business process, industry characteristic } \\
\text { trading partner resources, country characteristic }\end{array}$ & \\
\hline \multirow{3}{*}{ 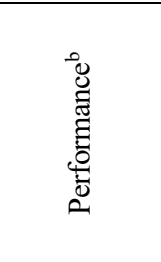 } & design of technology (3R) & $\begin{array}{l}\text { unification of organisational documents } \\
\text { and standardisation of processes, } \\
\text { communication and information flows }\end{array}$ \\
\hline & information technology (3R) & $\begin{array}{l}\text { communication and information } \\
\text { flows reorganisation }\end{array}$ \\
\hline & \begin{tabular}{|l|} 
other variables \\
appropriate use
\end{tabular} & $\begin{array}{l}\text { communication and information flows } \\
\text { reorganisation }\end{array}$ \\
\hline \multirow{5}{*}{$\cong \frac{\stackrel{\mathscr{E}}{:}}{:}$} & $\begin{array}{l}\text { strategy } \\
\text { investment allocation }\end{array}$ & \\
\hline & IS competencies (3R) & $\begin{array}{l}\text { communication and information flows } \\
\text { reorganisation }\end{array}$ \\
\hline & processes & processes unification \\
\hline & structure & $\begin{array}{l}\text { communication flows reorganisation, } \\
\text { unification of organisational documents }\end{array}$ \\
\hline & \begin{tabular}{|l} 
roles \\
business skills, knowledge and experience \\
technical skills, knowledge, and experience \\
behaviour and attitudes (3R) \\
\end{tabular} & $\begin{array}{l}\text { communication flows reorganisation, } \\
\text { users' trust }\end{array}$ \\
\hline \multirow{3}{*}{ 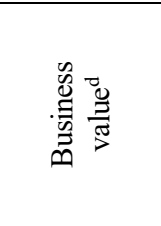 } & raw materials & \\
\hline & IT management roles and processes (3R) & $\begin{array}{l}\text { communication and information } \\
\text { flows reorganisation }\end{array}$ \\
\hline & $\begin{array}{l}\text { IT impacts: transformed business processes } \\
\text { enriched organisational intelligence } \\
\text { dynamic organisational structures }\end{array}$ & $\begin{array}{l}\text { unification of organisational documents } \\
\text { and standardization of processes }\end{array}$ \\
\hline \multirow{3}{*}{ 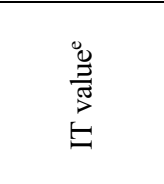 } & $\begin{array}{l}\text { hard IT management competencies } \\
\text { hard information management competencies }\end{array}$ & $\begin{array}{l}\text { unification of organisational documents } \\
\text { and standardisation of processes }\end{array}$ \\
\hline & soft competencies (3R) & \\
\hline & information orientation (3R) & $\begin{array}{l}\text { communication and information flows } \\
\text { reorganisation }\end{array}$ \\
\hline
\end{tabular}

${ }^{a}$ Melville N., Kraemer K., Gurbaxani V., Information technology and organizational performance. An integrative model of IT business value, MIS Quarterly, 2004, 28 (2), 283-322.

${ }^{b}$ Lucas H.C. Jr., The business value of information technology. A historical perspective and thoughts for future research, [In:] R.D. Banker, R.J. Kauffman (Eds.), Strategic information technology management. Perspectives on organizational growth and competitive advantage, Idea Group Publ., Harrisburg 1993, 359-374.

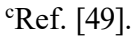

'Bharadwaj A., Sambamurthy V., Zmud R., IT capabilities. Theoretical perspectives and empirical operationalization, Proc. ICIS, 1999, 35.

eRef. [41]. 
- IT infrastructure - includes communication and networking managed using IT hardware, software, data, systems and its components with all applications [27],

- IT human capabilities - includes technical and managerial skills as well as technological knowledge [46],

- IT management capabilities - includes the alignment of skills between IT and the business fields [46],

- IT reconfiguration capabilities - includes the ability to adapt resources and IT capabilities for building competitive advantage [48].

All the above-mentioned authors consider IT as one of the tools of which basic capability is to support system approach and they list those support functions as one of the factors that build IT business value in the organisation $[12,36]$. There are a lot of IT business value models which can be useful in pinpointing the particular ways in which IT supports the integration and system approach to organisational management. The most commonly known models are presented in Table 1 . The presented models offer different approaches to the process of creating value for the organisation from using IT (3R), however, similar conclusions may be drawn from all of them.

First of all, many of them includes variables such as: Appropriate use, IT assets, IT resources in which authors underline the need for the 3R (reliability, resilience, and robustness) implementation to ensure the proper functioning of IT in organisation and the fact that without users' trust in the IT actual positive influence on their task completion and job performance, creating IT value for organisation is impossible. Second of all, the main conclusion from analysing them is that IT changes the communication and information flows in the organisation influencing business processes, management techniques, and information management systems. Madden and Jones [39] underline that IT can influence employees through reorganisation of those flows, both positively and negatively. Some of these positive effects include improved ability to do the job efficiently and to share information, ideas, and problem solutions with co-workers - all important aspects in the context of organisational integration. Moreover, IT influences the organisation' ability to standardise the processes and documents further impacting its overall system approach to the management. Table 1 contains the summary of each IT value models stages and the information concerning those which are crucial for creating the value connected with supporting integration within organisation and system approach to organisational management.

However, it is important to remember that IT can influence communication and information flows only when it is voluntarily used by all members of the organisation and is able to support all tasks it is meant to support in a proper way [4]. Hence, it may be assumed that the more reliable the IT, the more significant its influence on communication and information flow within the organisation is, and because of that on the overall integration of the organisation. As mentioned in Table 1, this influence is the main rea- 
son why IT supports the integration of organisation and system approach to organisational management. The concept of IT reliability is largely related not only to supporting system approach itself but also to the IT management and everyday use of IT in the organisation, which indirectly facilitate system approach. That is mainly because modern organisation are experiencing significant and immediate business impact when a critical system is unavailable in any way. It not only affects the business operations, and as such has an outsized effect on the business' perception of IT in an organisation and undermines its potential for supporting business processes. Is also affects the ability to be competitive on the market and may potentially impact customer satisfaction. Hence, it makes reliability a critical issue for modern managers and modern businesses. Therefore, it becomes obvious that IT reliability may indeed have an influence on business sustainability.

\section{IT reliability and business sustainability}

\subsection{Research method}

The aim of the empirical research is to verify the dependence between IT reliability and BS, including an examination of the impact of IT reliability on shaping the integrated BS logic. Therefore, the hypothesis states the more reliable IT, the more integrated the cognitive logic of BS is. The starting point for achieving the intended research goals is the formulation of a complex definition of each notion and measurement scales for them.

\section{The measurement of IT reliability}

Organisations usually manage a diverse portfolio of information systems (IS) that builds IT in it. Therefore, the notion of IT reliability connects directly to the concept of IS reliability, and IT in an organisation simply consists of all ISs in this organisation. That is why in many publications those two acronyms are used interchangeably. However, it is important to underline at the beginning that the reliability of IT or all ISs in an organisation is a different concept from the reliability of software or hardware, which are well-known and broadly discussed notions in literature. Hence, it is crucial not to confuse it with those embedded directly in computer sciences, which does not include the IT management standpoint. And this standpoint is a crucial part of obtaining and retaining a competitive advantage from the use of IT in an organisation.

Therefore, the reliability of IT in an organisation is understood as a measurable property of IS, useful for its control and management, identifying its quality level, pointing out potential problems [66], and it is directly linked to the efficiency of IT components, especially those that are critical to its proper operations. Therefore, it can be said 
that IS reliability in an organisation is a notion build by factors connected to 3 different IT theories. The first one is DeLone and McLean's [13] success model, the second one is Lyytinen and Hirschheim's [38] 4 types of IT failure, and the third one is TAM model [11]. The model of IT reliability in an organisation has been developed, tested [61] and presented in Fig. 3 as a model of reliability of IT in the organisation (underlining that IT in an organisation consists of all ISs). The reliability of IT in an organisation consists of 4 factors: reliability of the information included in IT in the organisation, reliability of support services offered for IT in the organisation, and reliability of ISs themselves, which also includes the fourth factor: the usability of IT. Each factor is built from a series of items, listed in Fig. 3.

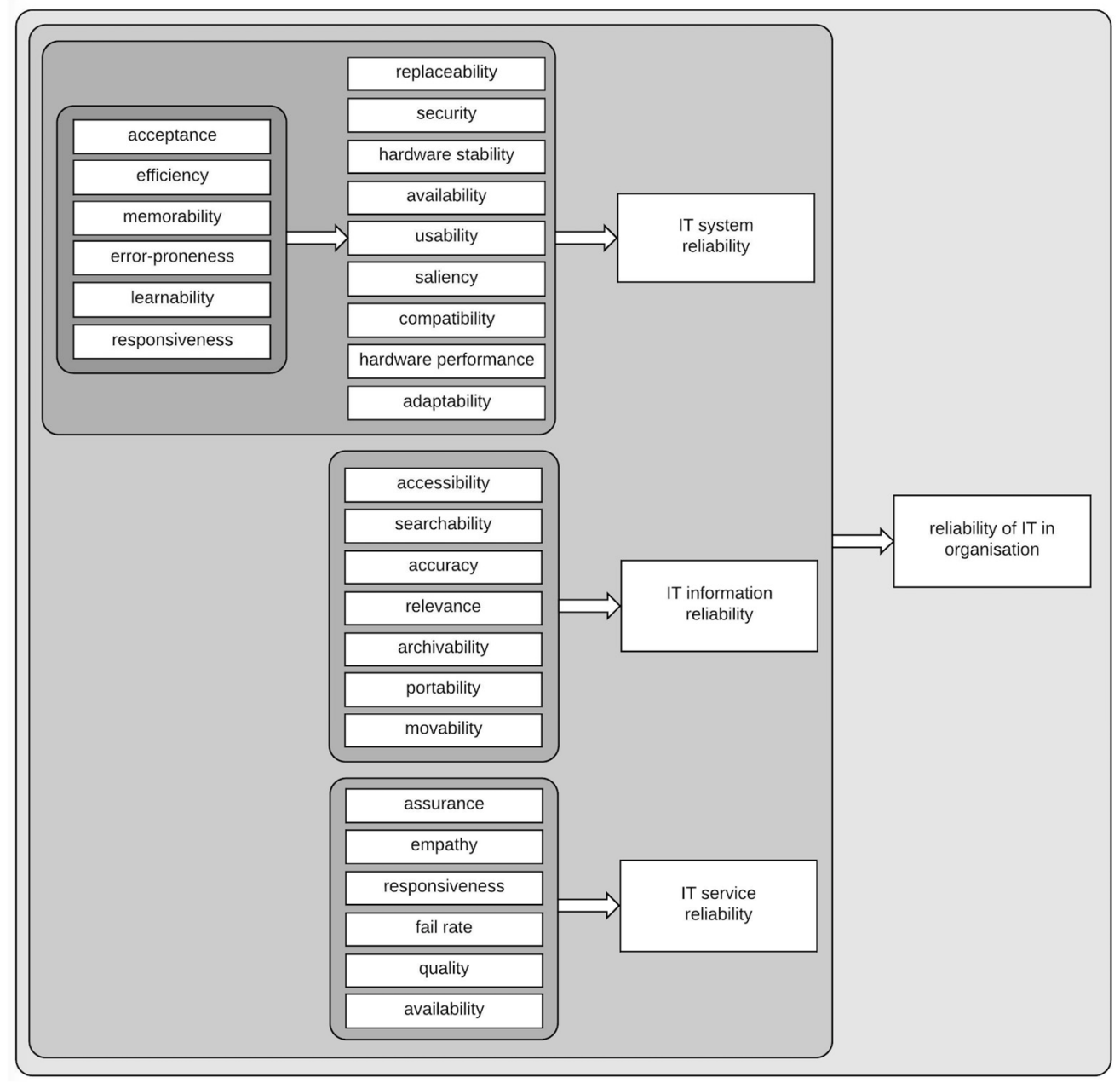

Fig. 3. Model of reliability of IT in the organisation. Source: [61] 
Moreover, based on the results of model testing, it can be said that reliable IT in an organisation is characterised as [61]:

- IT in which all ISs have a short response time, high availability connected with high security. However, the security should not be strained by the need for availability.

- IT in which information is easily accessible and the accuracy of them is guaranteed.

- IT in which all ISs are accepted by their users and easy to use.

- IT which has responsive and available support services.

The model is the basis for measurement scales created for the IT reliability analysed in this study.

\section{The measurement of business sustainability}

There is not any unambiguous, accepted concept of BS measurement, as there is still no agreement what BS is. Concepts of BS and sustainable business (company/enterprise/organisation) refer to the organisation's objectives [16], processes [53, 16], the organisation's characteristics [21, 57, 2], organisation state [51], and organisation's results $[21,26]$.

This study adopts the BS measurement approach based on the company's performance, which is the manifestation of how an organisation contributes to the improvement or deterioration of economic, environmental and social conditions, developments, and trends on the local, regional, or global level (in relation to GRI [23]). There still is no single, generally applicable definition used to disclose organisational performance regarding sustainable development [28]. Most of sustainability reporting ${ }^{4}$ and sustainable performance measurement scales are based on an organisation's impact on social development, environmental protection, and economic development, so on triple-bottom-line (TBL) popularised by Elkington [44]. In this elaboration, the TBL approach was adopted as a starting point.

The basis for the formulation of measures of sustainable performance was the analysis of studies devoted to the theoretical foundations of measurement systems oriented on sustainable development issues, and those discussing the existing sustainability assessment methodologies (e.g., [40, 62]).

The sustainable performance sub-constructs were operationalised by developing several items based on a literature review (Fig. 4). A resulting 7-item scale captures the extent to which organisations achieve economic performance, including financial and non-financial measures [42], and short-term and long-term measures [29], covering financial and market performance, quality performance and innovation performance from the concept of Maletic et al. [40]. However, modifications were made due to the

${ }^{4}$ Including UNEP/SustainAbility framework, Global Reporting Initiative's framework, the ACCA awards, and business case for measuring, managing and reporting environmental, social, and economic impacts. 
research objects - SMEs (for example, market share was excluded as irrelevant in the case of SMEs). The development of environmental performance measures is mainly based on the works of Boiral and Henri [5], Clarkson et. al. [6], Maletic et al. [40], and Campos et al. [6], and it captures the organisation's contribution to reducing the negative impacts that its activities may have on the biophysical environment [21]. To measure the social performance the extent to which organisations positively participate in creating healthy and friendly communities by implementing socially responsible business practices on the level of the organisation and the entire supply chain [10, 43, 63].

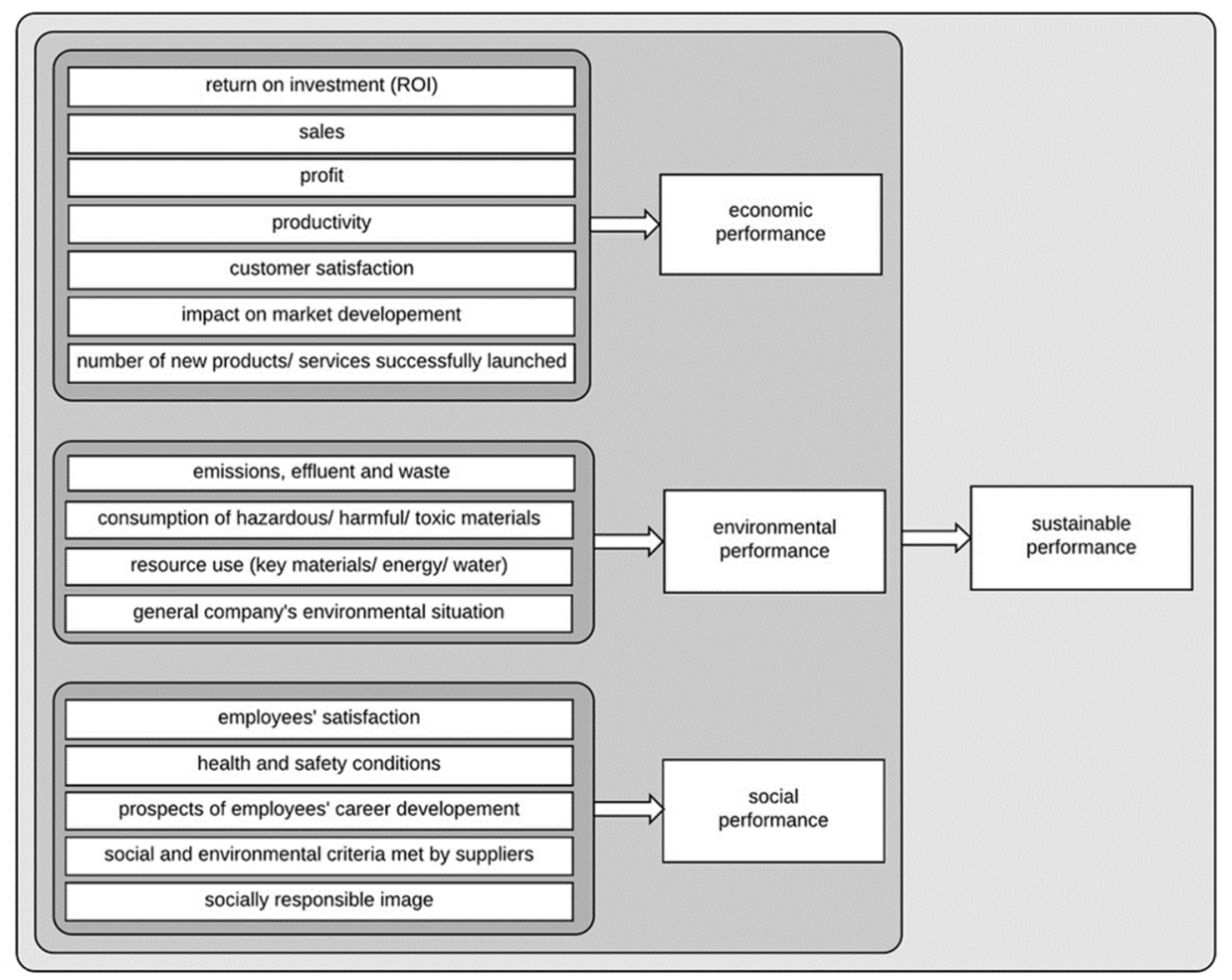

Fig. 4. Model of sustainable performance. Based on: [69]

\subsection{Study results}

The survey was conducted in order to identify the crucial factors that can be used to describe IT reliability in the organisation and BS, both of which were perceived by authors as somehow connected. The pilot survey was conducted in 2017 among the group of 100 organisation, indicating the issues concerning the ambiguity of several questions. It led to the collection of random answers given as a response to those questions. They 
were rewritten in order to obtain more reliable results, ensuring the informed response from the respondent. The main survey was conducted later in 2017, among small and medium (SMEs) organisations located in Poland, using online survey service SurveyMonkey ${ }^{\circledR}$. The survey was conducted on respondents' panel limited to managers working in SMEs located in Poland (no other limitations were introduced, which means that, e.g., the organisations come from various industries). Only one survey was carried out in one organisation. The research was anonymous. 400 valid responses were collected (the questionnaire was distributed among members of the respondents' panel until the assumed number (400) of responses was collected). Since the responses were collected using a properly prepared form, the online system counted only those that were full and correct. It is worth noting that the statistical population (SMEs operating in Poland) is finite but very large. Since the assumed (and obtained) sample covers only 400 organisations, the obtained results may have a character of preliminary conclusions, allowing for pointing directions for future research.

Respondents were asked to evaluate the IT in the organisation as based on the list of factors using the Likert scale (from very poor to very good with the middle point: fair). They were asked for a general opinion concerning the reliability of system, usage, information and service, and then to evaluate each factor constructing those 4 variables. Using the Likert scale to measure IT reliability seems to be an appropriate choice. First of all, the reliability of IT in an organisation is a subjective notion. Employees' own perspective and opinion concerning aspects of IT reliability is the best source of knowledge, since their perception matters the most, and that is because IT influences the organisation mainly through its potential to influence everyday work of the employees. Quantitative methods are commonly used to assess the software and hardware features linked to reliability. However, they do not give information concerning the actual perception of this notion within the organisation.

Respondents were also asked to rate the sustainable performance in the listed areas: economic, environmental, and social performance in last 3 years of operating using Likert scale (from well below expectations to well above expectations with the middle point: as expected). The evolution of the performance during the previous three years was conducted. In line with the literature, subjective measures of organisational performance were used [40]. Due to different industries and strategic priorities of the investigated organisations, performance data need to be adjusted to evaluate each organisation. For this purpose, an evaluation in comparison to the competition is usually needed. However, the objects of discussed research are SMEs, which are usually significantly weaker market participants. That is why respondents were asked to answer the questions by comparison to expectations. Most items were designed to evaluate the change of the investigated performance issues (e.g., reduction of resources use or customer satisfaction improvement), only a few were evaluated according to the state (e.g., prospects of employee's career development or the number of new products/services successfully launched). 
There were two main goals of this research. The first one was to develop comprehensive knowledge about two notions: IT reliability in the organisation, and the organisation's sustainable performance. The second one was to verify the proposed hypothesis and to identify the potential relation between IT reliability and sustainable performance.

In order to verify the hypothesis, the multidimensional correspondence analysis (MCA) correspondence was used. First, descriptive statistics were calculated for all the measured dependent and independent variables (Table 2).

Table 2. Descriptive statistics

\begin{tabular}{|l|c|c|c|c|c|c|c|c|}
\hline & Average & Median & Minimum & Maximum & $\begin{array}{c}\text { Lower } \\
\text { quartile }\end{array}$ & $\begin{array}{c}\text { Upper } \\
\text { quartile }\end{array}$ & $\begin{array}{c}\text { Standard } \\
\text { deviation }\end{array}$ & Variability \\
\hline IT reliability & 3.73 & 4.00 & 1.44 & 5.00 & 2.94 & 4.48 & 1.00 & 26.86 \\
\hline Information reliability & 3.71 & 4.00 & 1.43 & 5.00 & 2.86 & 4.43 & 1.02 & 27.48 \\
\hline System reliability & 3.74 & 4.00 & 1.39 & 5.00 & 3.30 & 4.50 & 0.98 & 26.32 \\
\hline Service reliability & 3.79 & 4.17 & 1.50 & 5.00 & 3.00 & 4.50 & 1.03 & 27.16 \\
\hline Sustainable performance & 2.85 & 2.88 & 1.00 & 5.00 & 2.10 & 3.46 & 0.90 & 31.63 \\
\hline Economic performance & 2.87 & 3.00 & 1.00 & 5.00 & 2.14 & 3.43 & 0.98 & 34.15 \\
\hline Social performance & 2.90 & 3.00 & 1.00 & 5.00 & 2.00 & 3.60 & 0.96 & 33.00 \\
\hline $\begin{array}{l}\text { Environmental } \\
\text { performance }\end{array}$ & 2.75 & 2.75 & 1.00 & 5.00 & 2.00 & 3.50 & 1.02 & 37.22 \\
\hline
\end{tabular}

The above show a very large spread of results, the coefficient of variation is greater than $20 \%$. It means that the average value and the variance may not be very precise measures of the analysed notions. Therefore, the nonparametric MCA model was used. Dependent variables were categorised into low, average, and high, using quartile division.

Multidimensional correspondence analysis (MCA) is an exploratory technique for categorized variables. It allows one to create models of links between different categories of answers. In the case of IT reliability and SP models, this analysis allows one to determine the strongest related variables (response categories) within the study group. As the impact force classifier, the model of distance maximisation from the reference point (i.e., the study group) was adopted. Because the main interest is the correspondence with the study group, the points in space for the three studied groups will be the reference points for other points (responses) and the quality of the solution. The quality of the solution is given by the equation:

$$
\beta=\frac{D^{2}\left(x_{0}, y_{0}\right)}{D_{\max }^{2}\left(x_{0}, y_{0}\right)}
$$

where $D^{2}\left(x_{0}, y_{0}\right)$ is the quotient of the square of the distance between the given point and the centre of the coordinate system, $D_{\max }^{2}\left(x_{0}, y_{0}\right)$ is the square of the distance in the coordinate system with the maximum number of dimensions. 
Point quality is analogous to the concept of shared variability in factor analysis. Therefore, a measure of the strength of the discriminative power of the answers to questions in relation to the study group is given by the classifier

$$
\forall p \in N, \quad \forall \beta_{p}>0.5, \quad \lambda_{p}(X, Y)=1-\frac{D\left(x_{p}, y_{p}\right)}{\max _{i}\left[D\left(x_{i}, y_{i}\right)\right]}
$$

where $D\left(x_{p}, y_{p}\right)$ is the distance between the point (response considered) from the study group and the quality of this point. This classifier determines the strength of the connection between each point and a study group.

Table 3. Matrix of MCA with the analysis of discriminative power

\begin{tabular}{|c|c|c|c|c|c|c|c|c|c|c|c|c|c|c|c|}
\hline \multirow{3}{*}{ Reliability } & \multirow{2}{*}{\multicolumn{2}{|c|}{$\begin{array}{c}\begin{array}{c}\text { Coordinate } \\
\text { system }\end{array} \\
\text { Factor }\end{array}$}} & \multirow{3}{*}{ 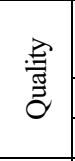 } & \multicolumn{12}{|c|}{ Performance } \\
\hline & & & & \multicolumn{3}{|c|}{ Sustainable } & \multicolumn{3}{|c|}{ Economic } & \multicolumn{3}{|c|}{ Social } & \multicolumn{3}{|c|}{ Environmental } \\
\hline & 1 & 2 & & $\mathrm{~L}$ & $\mathrm{M}$ & $\mathrm{H}$ & $\mathrm{L}$ & M & $\mathrm{H}$ & $\mathrm{L}$ & $\mathrm{M}$ & $\mathrm{H}$ & $\mathrm{L}$ & $\mathrm{M}$ & $\mathrm{H}$ \\
\hline IT: L & \begin{tabular}{|l|}
-1.307 \\
\end{tabular} & \begin{tabular}{|l|}
0.928 \\
\end{tabular} & 0.736 & 0.756 & 0.205 & 0.110 & 0.698 & 0.209 & 0.107 & 0.414 & 0.283 & 0.108 & 0.552 & 0.239 & 0.099 \\
\hline IT: M & -0.005 & -0.811 & 0.746 & 0.128 & 0.900 & 0.483 & 0.122 & 0.880 & 0.450 & 0.000 & 0.706 & 0.459 & 0.351 & 0.686 & 0.425 \\
\hline IT: $\mathrm{H}$ & 1.193 & 0.913 & 0.736 & 0.177 & 0.138 & 0.730 & 0.183 & 0.120 & 0.767 & 0.334 & 0.049 & 0.758 & 0.097 & 0.086 & 0.777 \\
\hline ITiability & & & & \multicolumn{3}{|c|}{0.497} & \multicolumn{3}{|c|}{0.471} & \multicolumn{3}{|c|}{0.221} & \multicolumn{3}{|c|}{0.294} \\
\hline INF: L & -1.485 & \begin{tabular}{|l|}
1.410 \\
\end{tabular} & 0.560 & 0.674 & 0.000 & 0.000 & 0.594 & 0.000 & 0.000 & 0.344 & 0.050 & 0.000 & 0.328 & 0.000 & 0.000 \\
\hline INF: M & -0.119 & -0.568 & 0.668 & 0.241 & 0.948 & 0.489 & 0.241 & 0.941 & 0.461 & 0.120 & 0.822 & 0.469 & 0.483 & 0.818 & 0.435 \\
\hline INF: H & \begin{tabular}{|l|}
1.171 \\
\end{tabular} & 0.973 & 0.643 & 0.189 & 0.125 & 0.709 & 0.195 & 0.107 & 0.746 & 0.350 & 0.040 & 0.737 & 0.098 & 0.076 & 0.757 \\
\hline Information & & & & \multicolumn{3}{|c|}{0.453} & \multicolumn{3}{|c|}{0.417} & \multicolumn{3}{|c|}{0.208} & \multicolumn{3}{|c|}{0.203} \\
\hline SYS: L & -1.303 & \begin{tabular}{|l|}
0.911 \\
\end{tabular} & 0.724 & 0.754 & 0.212 & 0.113 & 0.698 & 0.215 & 0.109 & 0.413 & 0.290 & 0.110 & 0.559 & 0.246 & 0.102 \\
\hline SYS: M & \begin{tabular}{|l|}
0.065 \\
\end{tabular} & -0.661 & 0.593 & 0.175 & 0.892 & 0.528 & 0.173 & \begin{tabular}{|l|}
0.874 \\
\end{tabular} & 0.497 & 0.070 & 0.727 & 0.505 & 0.399 & 0.731 & 0.471 \\
\hline SYS: H & 1.238 & 0.864 & 0.585 & 0.156 & 0.140 & 0.747 & 0.161 & 0.122 & 0.785 & 0.306 & 0.046 & \begin{tabular}{|l|}
0.776 \\
\end{tabular} & 0.082 & 0.083 & 0.797 \\
\hline System & & & & \multicolumn{3}{|c|}{0.502} & \multicolumn{3}{|c|}{0.479} & \multicolumn{3}{|c|}{0.233} & \multicolumn{3}{|c|}{0.326} \\
\hline SERV: L & -1.084 & \begin{tabular}{|l|}
0.489 \\
\end{tabular} & 0.609 & 0.700 & 0.404 & 0.213 & 0.679 & 0.412 & 0.205 & 0.413 & 0.509 & 0.208 & 0.744 & 0.469 & 0.192 \\
\hline SERV: M & 0.149 & -0.641 & 0.447 & 0.167 & 0.857 & 0.555 & 0.167 & 0.839 & 0.523 & 0.074 & 0.698 & 0.532 & 0.385 & 0.711 & 0.496 \\
\hline SERV: H & 1.311 & 0.932 & 0.611 & 0.129 & 0.099 & 0.727 & 0.132 & 0.080 & 0.765 & 0.280 & 0.000 & 0.755 & 0.039 & 0.034 & 0.782 \\
\hline Service & & & & \multicolumn{3}{|c|}{0.436} & \multicolumn{3}{|c|}{0.436} & \multicolumn{3}{|c|}{0.218} & \multicolumn{3}{|c|}{0.414} \\
\hline
\end{tabular}

L - low, M - medium, H - high, INF - information, SYS - system, SERV - service.

For each pair of two different variables in the model, there is a matrix (3) of coefficients (2)

$$
\forall p \in N, \forall \beta_{p}>0.5,\left\|\lambda_{p}(X, Y)\right\|=\left[\begin{array}{ccc}
\lambda_{p}\left(X_{1}, Y_{1}\right) & \cdots & \lambda_{p}\left(X_{1}, Y_{n}\right) \\
\vdots & \ddots & \vdots \\
\lambda_{p}\left(X_{m}, Y_{1}\right) & \cdots & \lambda_{p}\left(X_{m}, Y_{n}\right)
\end{array}\right]
$$


The discriminative power of $X$ to $Y$ is expressed by the equation:

$$
\forall X_{i} \in R, \lambda_{p}=\prod_{i=1}^{m} \max _{k}\left[\lambda_{i}\left(X_{i}, Y_{k}\right)\right]
$$

The results of the MCA are presented in Table 3 . The chosen model is statistically significant $\chi^{2}(529)=17855.4, p<0,01$. As based on empirical data, there is no reason to reject the $\mathrm{H}$ hypothesis: The more reliable IT is, the more integrated the cognitive logic of BS is.

The obtained results of the MCA show that low values of all the characteristics of independent IT variables influence low results in dependent variables of sustainable performance. Thus, all independent variables strongly determine the same levels of variables in dependent variables. As based on formula (4), discriminative powers were calculated between all combinations of $X \rightarrow Y$ variables. All independent variables on scales as well as results in general have the strongest influence on the overall score of sustainable performance, because the overall result has the maximum discriminative power. Moreover, the independent variables have a very strong effect on economic issues, then on environmental, and the worst on social ones.

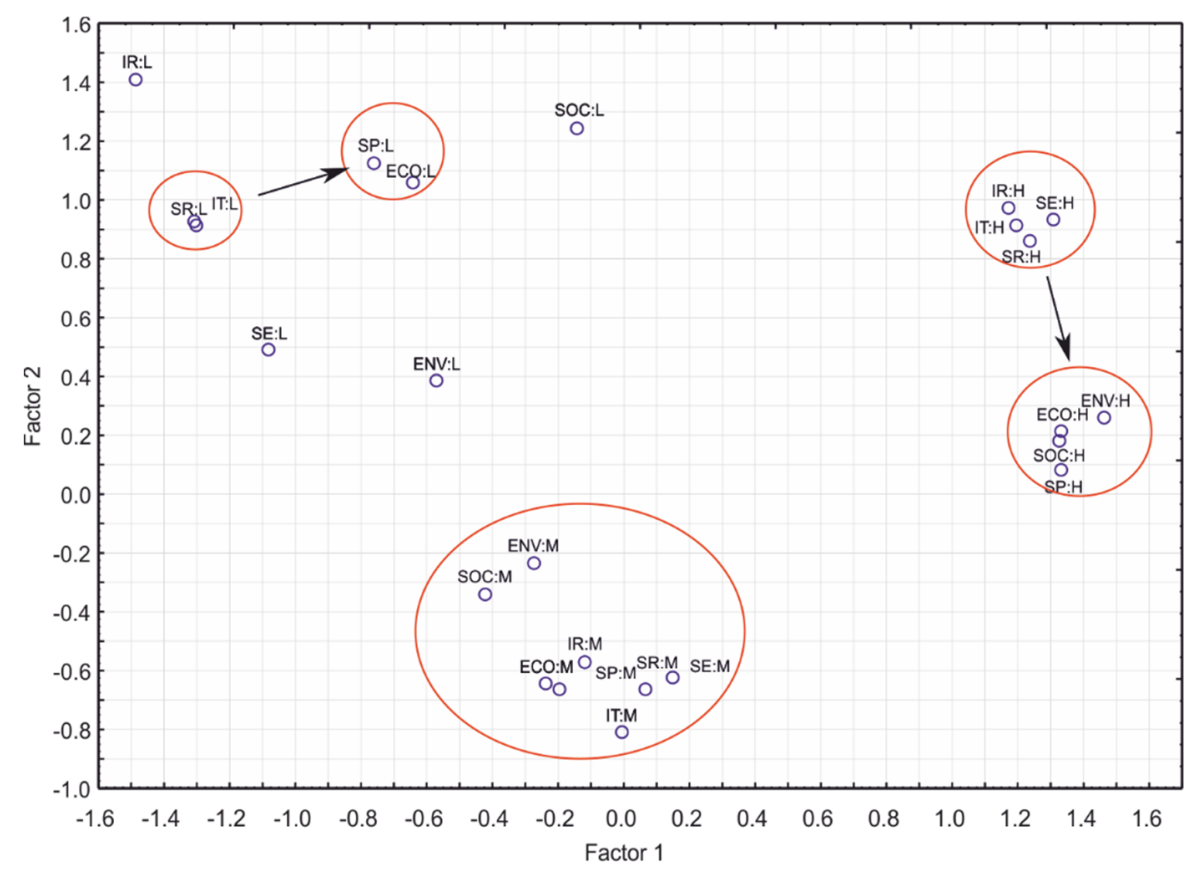

Fig. 5. Chart of projection of a multidimensional space of MCA characteristics into a two-dimensional space 
Figure 5 presents groups of characteristics that are most strongly related to each other and defines the directions of dependence.

\section{Conclusions}

Contemporary enterprises are increasingly communicating their commitment to socially and environmentally important matters, referring to broadly understood issues of sustainable development. Although there are common accusations that this is only rhetoric, and that the basic principles of enterprise functioning remain the same [7], it is difficult to disagree with the view of Przychodzen [51] that the challenges of sustainable development have an increasing impact on business.

Various approaches to BS can be found in the literature and management practice. Often, under the same wording, there are fundamentally different, sometimes mutually exclusive concepts. The typology of BS approaches quoted in the first part of the article forms the basis not only to identify the key differences between BS approaches but also indicates the directions of BS improvement in the context of sustainable development challenges. Integrative logic in relation to BS issues has been shown to be one of the key foundations for developing a sustainable organisation. It is only by breaking the reductionist logic that the role of the organisation in the broader context of sustainable development challenges can be taken into account. The diversity of different aspects of BS (multidimensionality of problems, differences in the needs of diversified stakeholders, dramatically different temporal and spatial perspectives) and their dynamic connections must be taken into account in the organisation's activities.

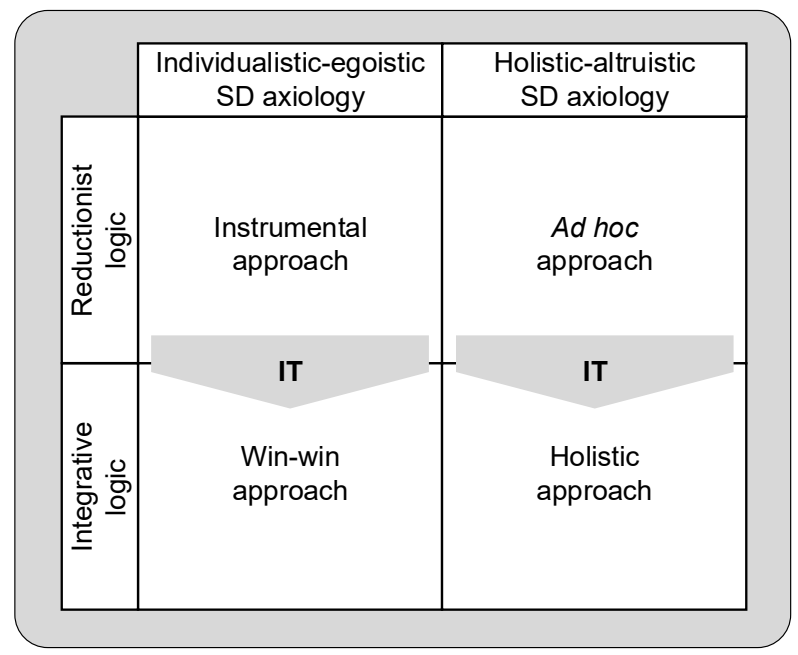

Fig. 6. IT role in shaping BS 
The strong theoretical foundations of IT participation in shaping BS is underlined in the previous parts of the article. To be exact, IT seems to be an important factor for building and shaping integrative logic crucial for BS (Fig. 6). It influences the reorganisation of the organisation's communication and information flows, fosters the unification of processes and documents within the organisation and allows organisation members to see their work as a small part of a big, integrated system.

Considering the above empirical research, it should be underlined that main aim of this article, which addresses the theoretical research gap outlined in the introduction to this paper and contributes to the theoretical concept of IT-BS relation, was achieved. IT can be considered as an important factor and tool shaping sustainable organisations. As it was pointed out earlier, nowadays IT is a crucial part of each organisation and there is no dispute that it adds value to it. However, profiting from its use is still unorganised in most organisations and proper identification of ways in which IT can benefit those organisation is a good first step. As based on the presented research conclusions, directions for the more conscious use of IT in sustainable organisations may be identified. First of all, simply using an IT in organisation is no longer sufficient. In order to obtain a full range of benefits needed for shaping sustainable organisation, there is a clear need for using a reliable IT, which is available, accessible, accepted and secure. The obtained results prove that IT reliability has a significant impact on BS in relation to the organisation's results, which are the manifestations of how an organisation contributes to the improvement or deterioration of economic, environmental, and social conditions. It should be emphasised that IT reliability was particularly important for achieving integrated economic, environmental, and social results of the organisation (higher than for individual dimensions of organisational performance).

It is important to underline that presented research has limitations - the model verification is based on two samples (the first, on 200 organisations operating in Poland, and the second, on 400 organisation operating in Poland), and further verification in different business contexts is required. The verification of relation between IT reliability and BS is solely based on one sample of 400 SMEs organisation operating in Poland. Therefore, the hypothesis requires further verification not only in different business contexts (different cultures, different types of organisations) but also in the light of influence from other elements of organisation (e.g., organisational culture, strategy, manufacturing technology, organisational structure, etc.). Moreover, there are for surely different factors influencing BS and the organisation' ability to implement and to use system approach which are not included in this empirical research and should be examined in the future as the potential moderators of the relation between IT and BS and also as separate variables.

Nevertheless, the research presented here is a solid first step in the process of hypothesis verification and it outlines the next steps for research in the relation between BS and IT reliability. Moreover, it allows for first conclusions to draw from the verifi- 
cation process, that are crucial for broadening our understanding of IT role in sustainable business: as an important mechanism for integrating commitments and actions to create sustainable value, conducive to undertaking comprehensive and proactive actions by the company.

\section{References}

[1] Amini M., Bienstock C.C., Corporate sustainability. An integrative definition and framework to evaluate corporate practice and guide academic research, J. Cleaner Prod., 2014, 76, 12-19.

[2] BAnsal P., Desjardine M.R., Business sustainability. It is about time, Strat. Org., 2014, 12 (1), 70-78.

[3] Barile S., SAViano M., IANDOlo F., CAlabrese M., The viable systems approach and its contribution to the analysis of sustainable business behaviors, Syst. Res. Behav. Sci., 2014, 31 (6), 683-695.

[4] BARNES, S.A., The differential impact of ICT on employees. Narratives from a hi-tech organisation, New Techn., Work Empl., 2012, 27, 120-132.

[5] Boiral O., HENRI J.F., Modeling the impacts of corporate commitment on climate change, Business Strat. Environ., 2012, 21 (8), 495-516.

[6] Campos L.M.S., De Melo Heizen D.A., Verdinelli M.A., Cauchick Miguel P.A., Environmental performance indicators. A study on ISO 14001 certified companies, J. Clean. Prod., 2015, 99, 286-296.

[7] CHO C.H., LAINe M., RoberTs R.W., RodRigue M., Organized hypocrisy, organizational façades, and sustainability reporting, Acc., Org. Soc., 2015, 40, 78-94.

[8] Clarkson P.M., Li Y., RichaRdSON G.D., VASVARI F.P., Revisiting the relation between environmental performance and environmental disclosure. An empirical analysis, Acc., Org. Soc., 2008, 33 (4), $303-327$.

[9] Clifton D., AmRAn A., The stakeholder approach. A sustainability perspective, J. Bus. Eth., 2011, 98 (1), 121-136.

[10] Crane A., Palazzo G., Spence L.J., Matten D., Contesting the value of creating shared value, Calif. Manage. Rev., 2014, 56 (2), 130-153.

[11] DAVIS F.D., A technology acceptance model for empirically testing new end-user information systems. Theory and results, Massachusetts Institute of Technology, 1986.

[12] De Wet W., Koekemoer E., Nel J.A., Exploring the impact of information and communication technology on employees work and personal lives, SA J. Ind. Psych., 2016, 42 (1), 1-11.

[13] Delone W.H., MCLean E.R., The Delone and McLean model of information systems success. A ten-year update, J. Manage. Inf. Syst., 2003, 19 (4).

[14] DoherTy N.F., Champion D., WANG L., A holistic approach to understanding the changing nature of organisational structure, Inf. Techn. People, 2010, 23, 3.

[15] Dragomirescu H., Bianco L., Tackling sustainability from a systemic perspective. A contextualized approach, Probl. Sust. Dev., 2017, 12 (1), 9.

[16] Dyllick T., MufF K., Clarifying the meaning of sustainable business. Introducing a typology from business-as-usual to true business sustainability, Org. Environ., 2016, 29 (2), 156-174.

[17] ESPINOSA A., PORTER T., Sustainability, complexity and learning. Insights from complex systems approaches, Learn. Org., 2011, 18 (1), 54.

[18] FATH B.D., Quantifying economic and ecological sustainability, Ocean Coastal Manage., 2015, 108, $13-19$.

[19] FEeny D.F., Ives B., In Search of Sustainability. Reaping Long-term Advantage from Investments in Information Technology, J. Manage. Inf. Syst., 1990, 7 (1), $27-32$.

[20] FIKSEL J., Sustainability and resilience. Toward a systems approach, Sust. Sci., Pract. Pol., 2006, 2 (2), 7. 
[21] GaO J., The evolution of business sustainability. Historical trajectory and structural relationships, The University of Western Ontario, Ontario 2008.

[22] GAO J., BANSAL P., Instrumental and integrative logics in business sustainability, J. Bus. Ethics, 2013, $112(2), 14$.

[23] GRI, Sustainability reporting guidelines ( $g 4)$, Global Reporting Initiative, 2013.

[24] Hahn T., Pinkse J., Preuss L., Figge F., Tensions in corporate sustainability. Towards an integrative framework, J. Bus. Ethics, 2015, 127 (2), 297-316.

[25] HARris D.L., TwOMEY D.F., The enterprise perspective. A new mind-set for competitiveness and sustainability, Comp. Rev.: Int. Bus. J., 2010, 20 (3), 258-266.

[26] Hart S.L., Milstein M.B., Creating sustainable value, Acad. Manage. Exec., 2003, 17 (2), 56-67.

[27] HaRTONO E., Li X., NA K.-S., SimpSON J.T., The role of the quality of shared information in interorganizational systems use, Int. J. Inf. Manage., 2010, 30 (5), 399-407.

[28] HĄBEK P., Disclosure of results in the field of sustainable development of enterprises, Org. Rev., 2013, 12, 20-27 (in Polish).

[29] Hongming X., Changyong L., Chunhui C., Relationships among market orientation, learning orientation, organizational innovation and organizational performance. An empirical study in the pearl river delta region of China, Front. Bus. Res. China, 2007, 1 (2), 222-253.

[30] IHLEN Ø., It is five minutes to midnight, and all is quiet - corporate rhetoric and sustainability, Manage. Comm. Quart., 2015, 29 (1), 145-152.

[31] JENnings P.D., ZANDBERGEN P.A., Ecologically sustainable organizations. An institutional approach, Acad. Manage. Rev., 1995, 20 (4), 1015.

[32] JEFFERS P.I., Embracing sustainability. Information technology and the strategic leveraging of operations in third-party logistics, Int. J. Oper. Prod. Manage., 2010, 30 (3), 260-287.

[33] Kahneman D., Thinking, Fast and Slow, MacMillan, 2011.

[34] Kettinger W.J., Grover V., GuHa S., Segars A.H., Strategic information systems revisited. A study in sustainability and performance, MIS Quart., 1994, 18 (1), 31-58.

[35] Korhonen J., SNÄKIN J.-P., Analysing the evolution of industrial ecosystems. Concepts and application, Ecol. Econ., 2005, 52 (2), 169-186.

[36] LASRADO F., BAGCHI T., A cross-cultural evaluation of the contemporary workplace and its managerial implications, Int. J. Bus., Manage. Soc. Sci., 2011, 2 (1), 1-15.

[37] LÜSCHER L.S., LEWIS M.W., Organizational change and managerial sensemaking. Working through paradox, Acad. Manage. J., 2008, 51 (2), 221-240.

[38] Lyytinen K., Different perspectives on information systems. Problems and solutions, ACM Comp. Surv. (CSUR), 1987, 19 (1), 5-46.

[39] Madden M., Jones S., Networked workers, Pew Internet and American Life Project, 2008.

[40] Maletic M., Maletic D., Dahlgaard J., Dahlgaard-PARK S.M., GomišceK B., Do corporate sustainability practices enhance organizational economic performance?, Int. J. Qual. Serv. Sci., 2015, 7 (2), 184-200.

[41] MARChAND M., RAYMOND L., Researching performance measurement systems. an information systems perspective, International J. Oper. Prod. Manage., 2008, 28 (7), 663-686.

[42] MAtić I., Measuring the effects of learning on business performances. Proposed performance measurement model, J. Amer. Acad. Bus., 2012, 18 (1), 278.

[43] McKenzIE S., Social sustainability. Towards some definitions, Hawke Research Institute Working Paper, Series No. 27, Hawke Research Institute, University of South Australia, Magill 2004.

[44] Milne M.J., GRAY R., W(h)ither ecology? The triple bottom line, the global reporting initiative, and corporate sustainability reporting, J. Bus. Ethics, 2013, 118 (1), 13-29.

[45] PAPUZIŃSKi A., The axiology of sustainable development. An attempt at typologization, Probl. Sust. Dev., 2013, 8 (1), 5. 
[46] PARK J.Y., IM K.S., KIM J.S., The role of IT human capability in the knowledge transfer process in it outsourcing context, Inf. Manage., 2011, 48 (1), 53-61.

[47] PARRISH B.D., Designing the sustainable enterprise, Futures, 2007, 39 (7), 846.

[48] Pavlou P.A., El Sawy O.A., The third hand. IT-enabled competitive advantage in turbulence through improvisational capabilities, Inf. Syst. Res., 2010, 21 (3), 443-471.

[49] Peppard J., Ward J., Beyond strategic information systems. towards an IS capability, J. Strat. Inf. Syst., 2004, 13 (2), 167-194.

[50] Porter M.E., Kramer M.R., Creating shared value, Harvard Bus. Rev., 2011, 89 (1), 62.

[51] Przychodzeń W.K., Sustainable enterprise. Theory, practice, evaluation, education, POLTEXT, Warsaw 2013 (in Polish).

[52] RobecoSAM, http://www.Sustainability-indices.Com/sustainability-assessment/index.Jsp, 2017.

[53] SAlZMANn O., IONESCU-SOMERS A., STEger U., The business case for corporate sustainability. Literature review and research options, Eur. Manage. J., 2005, 23 (1), 27-36.

[54] SAVITZ A.W., WeBER K., The triple bottom line. How today's best-run companies are achieving economic, social, and environmental success and how you can too, Jossey-Bass, San Francisco 2006.

[55] Shкroвot M., RopuszyŃSKa-Surma E., Polish and Ukrainian foresight into the directions for the innovation of power plants, Oper. Res. Dec., 2018, 28 (4), 47-70.

[56] Senge P.M., Smith B., Kruschwitz N., Laur J., Schley S., The necessary revolution. How individuals and organizations are working together to create a sustainable world, Crown Business, New York 2010.

[57] Smith P.A.C., Sharicz C., The shift needed for sustainability, Learn. Org., 2011, 18 (1), 73-86.

[58] Sterman J.D., Learning in and about complex systems, Syst. Dyn. Rev., 1994, 10 (2), 291-330.

[59] StubBs W., Cocklin C., Conceptualizing a sustainability business model, Org. Environ., 2008, 21, $103-127$.

[60] Tusubira F., Mulira N., Integration of ICT in organizations. Challenges and best practice recommendations based on the experience of makerere university and other organizations, International ICT Conference, Kampala, Uganda, 2004.

[61] TwOREK K., Reliability model of information systems in organization, Zeszyty Naukowe, Organizacja i Zarządzanie, Politechnika Śląska, Gliwice 2016, 88, 335-342.

[62] UnermAn J., CHAPMAN C., Academic contributions to enhancing accounting for sustainable development, Acc., Org. Soc., 2014, 39 (6), 385-394.

[63] Vallance S., Perkins H.C., Dixon J.E., What is social sustainability? A clarification of concepts, Geoforum, 2011, 42 (2), 342-348.

[64] Van MarrewiJK M., Werre M., Multiple levels of corporate sustainability, J. Bus. Ethics, 2003, 44 (2), 107-119.

[65] Washington H., Demystifying sustainability. Towards real solutions, Routledge, 2015.

[66] ZAHEDI F., Reliability of information systems based on the critical success factors. Formulation, MIS Quart., 1987, 11 (2), 187-203.

[67] ZGRZYwA-ZIEMAK A., Discrepancies and paradoxes in the conception of business sustainability, [In:] H. Czubasiewicz, P. Grajewski, J. Waśniewski (Eds.), Perspective of success factors for organizations of the 21st century, Faculty of Management, University of Gdańsk, Sopot 2016, 323-331 (in Polish).

[68] Zgrzywa-Ziemak A., Towards reporting for sustainable development, [In:] T. Dudycz, G. Osbert-Pociecha, B. Brycz (Eds.), Efficiency in business and economics, Springer, Cham 2018, 293-309.

[69] Zgrzywa-Ziemak A., Model of business sustainability, Oficyna Wydawnicza Politechniki Wrocławskiej, Wrocław 2019 (in Polish). 